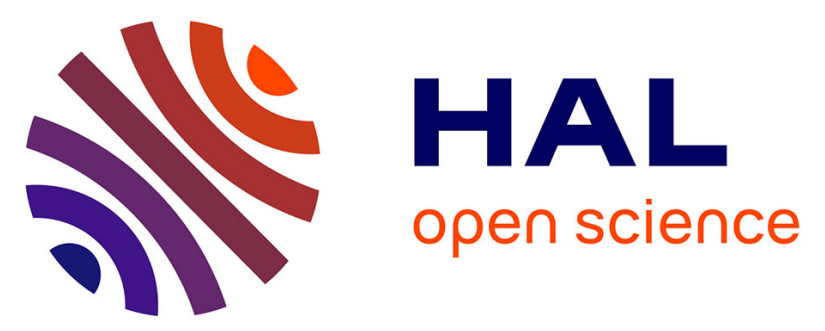

\title{
Chemotherapy use in end-of-life digestive cancer patients: a retrospective AGEO observational study
} Alexandra Lapeyre-Prost, Geraldine Perkins, Marie Vallee, Astrid Pozet, David Tougeron, Marianne Maillet, Christophe Locher, Johann Dreanic, Jean-Louis Legoux, Astrid Lièvre, et al.

\section{To cite this version:}

Alexandra Lapeyre-Prost, Geraldine Perkins, Marie Vallee, Astrid Pozet, David Tougeron, et al.. Chemotherapy use in end-of-life digestive cancer patients: a retrospective AGEO observational study. Clinics and Research in Hepatology and Gastroenterology, 2021, 45 (5), pp.101709. 10.1016/j.clinre.2021.101709 . hal-03268628

\section{HAL Id: hal-03268628 \\ https://hal.science/hal-03268628}

Submitted on 30 Jun 2021

HAL is a multi-disciplinary open access archive for the deposit and dissemination of scientific research documents, whether they are published or not. The documents may come from teaching and research institutions in France or abroad, or from public or private research centers.
L'archive ouverte pluridisciplinaire HAL, est destinée au dépôt et à la diffusion de documents scientifiques de niveau recherche, publiés ou non, émanant des établissements d'enseignement et de recherche français ou étrangers, des laboratoires publics ou privés. 


\section{Chemotherapy use in end-of-life digestive cancer patients: a retrospective AGEO observational study}

Alexandra Lapeyre-Prost ${ }^{1}$, Geraldine Perkins ${ }^{1}$, Marie Vallee ${ }^{2}$, Astrid Pozet $^{3}$, David Tougeron ${ }^{4}$, Marianne Maillet ${ }^{5}$, Christophe Locher ${ }^{6}$, Johann Dreanic $^{7}$, Jean-Louis Legoux ${ }^{8}$, Astrid Lièvre ${ }^{9,10}$, Cedric Lecaille ${ }^{11}$, Jean-Marc Sabate ${ }^{12}$, Florence Mary ${ }^{13}$, Franck Bonnetain ${ }^{3}$, Hélène Jaulmes-Bouillot ${ }^{14}$, Florence Behal ${ }^{14}$, Bruno Landi ${ }^{1}$, Julien Taieb ${ }^{1}$

${ }^{1}$ Université de Paris, Department of Gastroenterology and GI Oncology, Georges Pompidou European Hospital, AP-HP, Paris, France

${ }^{2}$ Oncology Department, Poitiers University Hospital, Poitiers, France

${ }^{3}$ Methodology and Quality of Life in Oncology Unit, INSERM U1098, University Hospital of Besançon, Besançon, France

${ }^{4}$ Gastroenterology Department, Poitiers University Hospital, Poitiers, France

${ }^{5}$ Department of Gastroenterology, St-Louis Hospital, AP-HP, Paris, France

${ }^{6}$ Department of Gastroenterology, General Hospital of Meaux, Meaux, France

${ }^{7}$ Department of Gastroenterology, Cochin Hospital, AP-HP, Paris, France

${ }^{8}$ Department of Gastroenterology and Digestive Oncology, Centre Hospitalier Regional, Orléans, France

${ }^{9}$ Department of Medical Oncology, Institut Curie, Hôpital René Huguenin, Saint-Cloud, France

${ }^{10}$ Department of Gastroenterology, Rennes University Hospital, Rennes 1 University, Rennes, France

${ }^{11}$ Department of Gastroenterology, Polyclinique Bordeaux Nord Aquitaine, Bordeaux, France

${ }^{12}$ Department of Gastroenterology, Louis Mourier Hospital, AP-HP, Colombes, France

${ }^{13}$ Gastroenterology and Digestive Oncology, CHU Avicenne, AP-HP, Bobigny, France;

${ }^{14}$ Palliative care unit, Georges Pompidou European Hospital, AP-HP, Paris, France

Correspondence to:

Alexandra Lapeyre-Prost

Hepatogastroenterology and Digestive oncology, Université de Paris, Georges Pompidou

European Hospital, 20 rue Leblanc, 75015 PARIS, FRANCE

Tel: +33156093551

Email: alapeyre21@gmail.com> 
Highlights

- Two-thirds of digestive cancer patients receive chemotherapy within the last 3 months of life

- Young patients and patients with aggressive disease receive more end-of-life chemotherapy

- Palliative care team intervention is associated with less administration of chemotherapy in the last month of life

- Patients who receive chemotherapy in the last months of life die more often in oncology units than at home or in palliative care unit

\begin{abstract}
Background: The use of chemotherapy (CT) near the end-of-life (EOL) is an important issue in oncology since it could degrade quality of life. CT near EOL is still poorly studied, with no dedicated study in gastrointestinal (GI) cancer patients.
\end{abstract}

Aim: To analyze in GI cancer patients the factors associated with the use of CT within 3-and 1-month before patients' death. 
Methods and participants: All consecutive patients who died from a Gl cancer in 10 French tertiary care hospitals during 2014 were included in this retrospective study. Clinical, demographical and biological data were collected and compared between patients receiving or not CT within 3- and 1-month before death. Variables associated with overall survival (OS) was also determined using of univariate and multivariate analyses with a Cox model.

Results: Four hundred and thirty-seven patients with a metastatic GI cancer were included in this study. Among them, 293 pts (67.0\%) received CT within 3-months before death, and 121 pts (27.7\%) received CT within 1-month before death. Patients receiving CT within 3months before death were significantly younger (median age: 65.5 vs 72.8 years, $p<0.0001$ ), with a better PS (PS 0 or 1: 53.9 vs $29.3 \%, p<0.0001$ ) and a higher albumin level (median: 32.8 vs $31.0 \mathrm{~g} / \mathrm{L}, \mathrm{p}=0.048$ ). Similar results were found for CT within 1 month before death. Palliative care team intervention was less frequent in patients who received CT in their last month of life (39.7\% vs $51.3 \%, p=0.02)$. In multivariate analysis, median OS from diagnosis was shorter in the group receiving CT within 1-month before death $(H R=0.59 ; 95 \% \mathrm{Cl}[0.48-0.74])$.

Conclusion: In GI-cancer patients, CT is administered within 3-and 1- month before death, in two and one third of patients, respectively. Patients receiving CT within 1-month before death, had more aggressive disease with poor OS. Palliative care team intervention was associated with less administration of CT in the last month of life. These results highlight the need to better anticipate the time to stop CT treatment in the end-of-life and the importance of an active collaboration between oncology and palliative care teams. 
Keywords : End-of-life chemotherapy ; palliative care ; digestive oncology ; palliative care team ; aggressiveness of end-of-life care
Abbreviations :
EOL : end-of-life
CT : chemotherapy
GI : gastrointestinal
OS : overall survival
QOL : quality of life
PCU : palliative care unit
PCT : palliative care team 


\section{INTRODUCTION}

The need to improve the quality of care near end-of-life (EOL), including symptom control, choice of death place, psychosocial and spiritual supports is increasingly recognized by clinicians. Paradoxically, aggressiveness of cancer care near death has increased over time $(1,2)$ possibly favored by increasing treatment possibilities. Indeed, studies have shown that 66 to $83 \%$ of patients followed for solid tumors receive chemotherapy (CT) in the last 3 months of life, and 20 to $40 \%$ within 30 days before death, although CT use in the last month of life has been recognized as an indicator of too aggressive EOL medical care (3-5). The use of CT in advanced cancer patients, including gastrointestinal (GI) cancer patients, intends to improve both life quantity (overall survival; OS) and quality (quality of life; QOL) by controlling symptoms related to tumor spread $(6,7)$. However, when CT is administrated near EOL, improvement in patients' QOL is uncertain (8) due to poor efficacy of CT, treatment-related toxicity and often delay in using palliative care resources, shown to be effective for QOL improvement (9). The use of CT in EOL also increases frequency of hospital admissions and in-hospital deaths. Additionally, earnings on patient survival has not been demonstrated with this practice (10).

Recently, a study conducted in lung cancer patients reported that early palliative care is associated with a reduced exposure to CT near death and a better QOL and survival (11). Prolonged use of CT might be due in part to the complexity of accurate evaluation of cancer patients' prognosis, probably overestimated by the referent physician $(12,13)$. It has been shown that intervention of a palliative care team improves EOL quality but also decreases EOL CT administration (14,15). An active collaboration between the referent oncologist and the palliative care team during onco-palliative multidisciplinary meetings seems thus recommended (15). Care planning discussions with the patient and his close relatives together 
with early communication on EOL have also been associated with less aggressive EOL treatments and consequently more appropriate and less aggressive cares in EOL $(16,17)$. A better characterization of patients receiving CT during EOL may help to improve patient care in this difficult period of the patients' journey to focus on patients' QOL. Most of published studies on EOL CT included heterogeneous patients with different malignancies and anti-cancer treatments, although the level of cancer therapies near the EOL seems to vary across different cancer types (18). To our knowledge no dedicated study has been conducted in GI cancer patients in whom the CT practices in EOL remains poorly documented. The objective of this study was to describe, in GI cancer patients, CT practices during EOL and factors associated with its use within three and one month before death. 


\section{METHODS}

\section{Study design}

We conducted a retrospective, multicenter, observational study. All patients diagnosed with a GI cancer, followed in 10 French specialized oncology units, part of the Association des Gastro-Entérologues Oncologues (AGEO) network, that died in 2014 were included.

\section{Data collection}

Baseline patient socio-demographic data (age at diagnosis, sex, center), tumor type (site and histology) at the time of diagnosis together with disease history (number of CT lines, CT regimens) were collected retrospectively by consulting medical records. Additionally, clinicobiological data focusing on patient's general condition (WHO performance status (PS), albumin level) and disease extension (metastatic sites) 3 months before death were also collected. The number and length of hospital stay and the administration of parenteral nutrition in the last 3 months of life were recorded. We finally identified patients for whom a palliative care team had intervened and data on cause and place of death were recorded.

\section{Statistical analysis}

\section{Description of population}

The characteristics of the population were described as belonging to one of the four following groups: patients who received CT within respectively 3 or 1 month before death or patients who have not received CT within 3 or 1 month before death. Categorical variables were described by frequency and percentage and compared between groups using Pearson's chisquared test. The mean, standard deviation, median and range were calculated for quantitative variables. The average of the variables was compared between groups using the t-test for variables with normal distribution or using the Wilcoxon test for the other variables. A Cox 
proportional regression model was used to balance for baseline clinical variables associated with CT within 1-month before death.

\section{Survival analysis}

Overall survival (OS) was defined as the delay from the date of diagnosis to the date of death from any cause. OS was estimated using Kaplan Meier method, described using median and its $95 \%$ confidence interval (95\% CI), and compared using log-rank test. Univariate Cox regression was used to estimate hazard ratio (HR) with its $95 \%$ CI. A multivariate Cox proportional hazards regression model was performed using all variables with a $\mathrm{p}<0.05$ in univariate analysis. The assumption of risks proportionality and log-linearity were verified for each variable. Correlations between all variables were explored. In case of strong correlation between two variables, either one variable was included in the multivariate model. Survival curves were computed using the Kaplan-Meier method and compared using the Log Rank test. Statistical analyses were conducted using the SAS ${ }^{\circledR} 9.4$ (SAS Institute, Cary, NC). 


\section{RESULTS}

\section{Patient characteristics}

Four hundred thirty-seven patients with GI cancer and deceased in 2014 were included in this retrospective study. Among them, 293 (67.0\%) received CT within 3 months before death and $121(27.6 \%)$ in the month before death (Table 1). Median age at diagnosis was 67.5 years (27.2-98.6), and $64.3 \%$ of patients were men. Seventy-five percent of patients were treated in university hospital.

\section{Patient characteristics according to the administration of EOL CT (3 vs 1 month before}

\section{death)}

Patients receiving CT during 3 or 1 month before death were significantly younger than patients who did not (Median age 65.5 vs 72.8 years, $\mathrm{p}<0.0001$ and 65.4 vs 67.9 years, $\mathrm{p}=0.036$ respectively). Women received significantly more CT in the month before death than men $(\mathrm{p}=0.03)$. Patients treated in university hospitals received more CT in the last month of life than those treated in another category of care center (non-university hospitals, private centers, comprehensive cancer centers) $(\mathrm{p}=0.04)$. In multivariate analysis, age at diagnosis, gender, and WHO performance status 3 months before death were significantly associated with CT one month before death (supplementary data).

\section{Tumor characteristics}

Thirty six percent of patients had colorectal cancer, $28 \%$ pancreatic cancer, $10 \%$ gastric cancer and $26 \%$ other GI tumors. The primary tumor localization was not associated with the prescription of CT in the three months or in the month before death. Patients who had received at least 3 prior lines of $\mathrm{CT}$ received more $\mathrm{CT}$ in the three months before death than patients who did not $(\mathrm{p}=0.002)$. In patients receiving CT during their last 30 days, pancreatic (33\%) and colorectal cancer (30\%) were the most represented. About half of the patients 
(53.3\%) had only one metastatic site three months before their death. Patients receiving CT within 3-months before death had significantly more metastatic sites ( $\geq 2$ metastatic sites : $51.2 \%$ vs $37.5 \%, \mathrm{p}=0.002$ ) and had more often liver or peritoneal metastases (liver: $66.9 \%$ vs $55.6 \%, p=0.02$; peritoneum: $34.5 \%$ vs $23.6 \%, p=0.02)$ than those who did not. Patients who received CT in the last three months or in the last month of life had a significant better PS and albumin levels than patients who did not (Table 1).

\section{Toxicities and other treatments}

Sixteen percent of patients who received CT in the last three months of life experienced grade 3 or 4 toxicities and these severe toxicities were even more frequent in patients who received chemotherapy in the last month of life, compared to those who did not $(27.3 \%$ vs $12.03 \%, \mathrm{p}$ $<0.0001)$. Thirty-nine patients $(9 \%)$ received another antitumor treatment than chemotherapy in their last 3 months of life. Among them, 26 had radiotherapy, 4 chemoembolization and 9 surgery. About three-quarters of patients who received radiotherapy had bone metastases. The purpose for the surgery was not specified. No difference was observed in the practice of EOL CT between patients that received another antitumor treatment and those who did not.

\section{Supportive Care}

Forty-eight percent of patients were referred to a palliative care team (PCT). A PCT intervened less often in patients who received CT in their last month of life, compared to those who did not (40\% vs 51\%, p = 0.02), (Table 2). The number of patients with at least one hospitalization in the three months before death and the duration of hospitalization were not increased in patients receiving CT. Patients who received CT in their last three months were more likely to receive parenteral nutrition $(\mathrm{p}=0.01)$. 


\section{Cause of death and end of life management}

The median time between the last infusion of CT and death was 45 days (0-3962 days). Cause of death was an acute event (not related to cancer evolution) for $23.1 \%$ of patients receiving CT in their last month of life compared with only $8.2 \%$ for those who did not $(p=0.0003)$. Patients who received CT in their last month of life were more likely to die in a medical GI oncology unit than in a palliative care unit $(P C U)$ or at home $(p=0.0009)$. The median time between transfer to PCU and death was significantly shorter for patients receiving CT during their last month of life, compared to those who did not (median time 7 vs 14 days respectively, $\mathrm{p}=0.02)$.

\section{Analyses of overall survival}

For the 437 patients analysed, the median overall survival was 12.1 months. In univariate analysis, median OS was 7.7 months (95\%CI [6.4-11.0]) in patients receiving CT in the last month of life and 13.5 months (95\%CI [11.8-16.5]) in the group without CT in the last month (HR 0.65; 95\%CI [0.52-0.8]; $\mathrm{p}<0.0001$ ). The other variables that influenced OS in univariate analysis were center $(\mathrm{p}=0.08)$, age at diagnosis (continuous variable) $(\mathrm{p}<0.0001)$, primary tumor location $(\mathrm{p}<0.0001)$, histology $(\mathrm{p}<0.0001)$. Therefore, these variables, excepted histology which presented a strong correlation with primary tumor location, were included in a multivariate Cox's model that showed that no CT in the last month (HR 0.58; 95\%CI [0.460.72]; $\mathrm{p}=<0.0001)$ was independently associated with a longer OS together with being treated in non-university hospital, younger age at diagnosis and having a colorectal cancer (Table 3).

\section{DISCUSSION}

In this study, we retrospectively analyzed a series of 437 patients with digestive cancer deceased in 2014. We have identified that young patients and those with rapidly progressive disease receive more EOL CT. Furthermore, intervention of a palliative care team was associated with less prescription of EOL CT. 
The influence of age on EOL CT administration may be partly due to difficulties to accept EOL and treatment failure, by young patients themselves, their families, but also the referent physician. Association between young age and EOL CT in patients with GI cancer has been previously reported $(19,20)$. In a recent French study carried out with the French social security (CNAM), including 15361 colorectal cancer patients who died in 2015, CT administration in the last month of life concerned $15 \%$ of all patients, $26 \%$ of patients aged less than 60 years, $18 \%$ of patients between 70 and 79 and $7 \%$ of patients over 80 years old (20). Several studies suggested that patients with tumors known to be chemo-sensitive may receive more EOL CT than others $(18,21,22)$. However, as others $(23-25)$, we did not find any association between primary tumor location and EOL practices.

Our results on survival suggest that patients with a rapidly progressive disease receive more chemotherapy near EOL than those with a long disease history. We also identified the number of prior CT lines as an important factor influencing EOL CT practices, as already reported previously (22).

University hospitals (26) or comprehensive cancer centers with a high bed density (27) or with a high annual volume of CT (23) have already been identified as structures where patients with solid tumors receive more CT during EOL. Development of therapeutic options in digestive oncology, including the provision of new molecules such as targeted molecular therapies, oral chemotherapies and rechallenge strategies, may contributes to increase late prescriptions of CT. Specialized centers are up-to-date with all these therapeutic approaches and generally authorized to prescribe them, but also more likely to suggest inclusion in clinical trials testing new molecules. These can explain the differences noted in EOL practices between university hospitals and anti-cancer centers as compared to others.

In our study, patients receiving CT in their last month of life died more often from an acute cause (not directly related to cancer evolution) than those who did not. Together with a 
significantly higher rate of grade 3 or 4 toxicity in these patients it suggests that EOL CT may seriously impair EOL quality. According to previous study results $(28,29)$, we found that the multidisciplinary work with a PCT significantly influences CT practices in the last month of life. Indeed, current recommendations indicate that discussions about palliative care team should take place as early as possible in the management of the incurable cancer patients, with evidence of clinical benefit $(11,31,32)$ for improving QOL and reduced futile chemotherapy and the EOL terms of quality of life (9). A recent work analyzing intensity of care in academic center and comprehensive cancer center, shows that the intervention of a PCT more than 30 days before deaths was associated with lower likelihood of receiving CT near death (30). In a study by Colombet et al., only active collaboration between referring physicians and PCT (but not the single intervention of PCT) reduced CT administration during the last 14 days of life (15), which shows the importance of multidisciplinary discussions concerning palliative care that involve complex EOL decisions. Place of death and admission to palliative care unit more than a week before death are considered as key factors in EOL quality $(3,33)$. In our work, patients receiving a CT in the last month of their lives died more in medical GI oncology unit than at home or in PCU, as reported in other studies $(16,20)$. Moreover, the delay between transfer to PCU and death was significantly reduced in our patients receiving CT in the month prior to death. Indeed, the use of EOL CT could delay or prevent the setting up of palliative care and thus contribute to the deterioration of the EOL quality.

One of the strengths of our study is that our cohort was dedicated to GI tumors and includes a significant number of patients belonging to several categories of health centers and selected over a year only which suggests quite homogeneous care for each type of GI cancer enrolled. In addition, we studied the relationship between EOL CT administration and patient survival. The main limitation is its retrospective approach, with missing data (such as WHO-PS status). In addition, we were unable to collect some data that could have influenced the use of EOL 
$\mathrm{CT}$, such as patient comorbidities, presence of symptoms not controlled by palliative care as well as the feelings of patients and caregivers. Indeed, it has been shown that patient psychological factors, such as anxiety or depression, can influence EOL CT use (34). In addition, age and experience of the practitioner in charge also certainly play a role.

Oncologists may also experience difficulties in being objective and correctly assessing the prognosis of their patients $(12,13)$. Therefore, research and development of prognostic tools are of paramount importance. Thus, prognostic scores such as Barbot score (35), GPS / PPS (36) or a simple score like that developed in the French multicentre PRONOPALL study-(37) can already be very useful to accurately predict patients life expectancy and avoid the use of CT in the last months of life.

\section{CONCLUSION}

This retrospective study shows that, in a population of GI cancer patients, those who received $\mathrm{CT}$ in their last month of life, were younger patients with rapidly progressive disease sometimes heavily pretreated and that they die more often in GI oncology units than at home or in PCU. These findings suggest that the EOL CT administration could be explained by the difficulty, for the patient, his relatives and medical team, in accepting a refractory disease and its poor prognosis. The intervention of a PCT was associated with less prescriptions of CT in the last month of life. Multidisciplinary discussions involving palliative care teams are thus necessary to better anticipate the time to stop CT in the EOL. A prospective evaluation using more EOL quality indicators and taking into account medical, private, psychological and social aspects could be very useful in the future to better understand EOL practices determinants and improve patients EOL care.

Alexandra Lapeyre-Prost, Geraldine Perkins, Marie Vallee, Astrid Pozet, David Tougeron, Marianne Maillet, Christophe Locher, Johann Dreanic, Jean-Louis Legoux, Astrid Lièvre, Cedric Lecaille, Jean-Marc Sabate, Florence Mary, Franck Bonnetain, Hélène Jaulmes- 
Bouillot, Florence Behal, Bruno Landi, Julien Taieb have no conflicts of interest related to this work to declare 


\section{BIBLIOGRAPHY}

1. Earle CC, Neville BA, Landrum MB, Ayanian JZ, Block SD, Weeks JC. Trends in the aggressiveness of cancer care near the end of life. J Clin Oncol Off J Am Soc Clin Oncol. 2004 Jan 15;22(2):315-21.

2. Lee H, Chun K, Moon D, yeon H, Lee S, Lee S. Trends in receiving chemotherapy for advanced cancer patients at the end of life. BMC Palliat Care. 2015;14(1):4.

3. Earle CC, Park ER, Lai B, Weeks JC, Ayanian JZ, Block S. Identifying potential indicators of the quality of end-of-life cancer care from administrative data. J Clin Oncol Off J Am Soc Clin Oncol. 2003 Mar 15;21(6):1133-8.

4. Bekelman JE, Halpern SD, Blankart CR, Bynum JP, Cohen J, Fowler R, et al. Comparison of site of death, health care utilization, and hospital expenditures for patients dying with cancer in 7 developed countries. Jama. 2016;315(3):272-283.

5. Wright AA, Zhang B, Keating NL, Weeks JC, Prigerson HG. Associations between palliative chemotherapy and adult cancer patients' end of life care and place of death: prospective cohort study. Bmj. 2014;348:g1219.

6. Cunningham D, Pyrhönen S, James RD, Punt CJ, Hickish TF, Heikkila R, et al. Randomised trial of irinotecan plus supportive care versus supportive care alone after fluorouracil failure for patients with metastatic colorectal cancer. Lancet Lond Engl. 1998 Oct 31;352(9138):1413-8.

7. Burris HA, Moore MJ, Andersen J, Green MR, Rothenberg ML, Modiano MR, et al. Improvements in survival and clinical benefit with gemcitabine as first-line therapy for patients with advanced pancreas cancer: a randomized trial. J Clin Oncol Off J Am Soc Clin Oncol. 1997 Jun;15(6):2403-13.

8. Prigerson HG, Bao Y, Shah MA, Paulk ME, LeBlanc TW, Schneider BJ, et al. Chemotherapy Use, Performance Status, and Quality of Life at the End of Life. JAMA Oncol. 2015 Sep 1;1(6):778.

9. Kaasa S, Loge JH, Aapro M, Albreht T, Anderson R, Bruera E, et al. Integration of oncology and palliative care: a Lancet Oncology Commission. Lancet Oncol. 2018;19(11):e588-653.

10. Saito AM, Landrum MB, Neville BA, Ayanian JZ, Earle CC. The effect on survival of continuing chemotherapy to near death. BMC Palliat Care. 2011;10:14.

11. Temel JS, Greer JA, Muzikansky A, Gallagher ER, Admane S, Jackson VA, et al. Early palliative care for patients with metastatic non-small-cell lung cancer. N Engl J Med. 2010 Aug 19;363(8):733-42.

12. Christakis NA, Smith JL, Parkes CM, Lamont EB. Extent and determinants of error in doctors' prognoses in terminally ill patients: prospective cohort studyCommentary: Why do doctors overestimate?Commentary: Prognoses should be based on proved indices not intuition. BMJ. 2000 Feb 19;320(7233):469-73.

13. Glare P, Virik K, Jones M, Hudson M, Eychmuller S, Simes J, et al. A systematic review of physicians' survival predictions in terminally ill cancer patients. BMJ. 2003 Jul 24;327(7408):195.

14. Jang RW, Krzyzanowska MK, Zimmermann C, Taback N, Alibhai SMH. Palliative Care and the Aggressiveness of End-of-Life Care in Patients With Advanced Pancreatic Cancer. JNCI J Natl Cancer Inst. 2015 Jan 20;107(3):dju424-dju424.

15. Colombet I, Montheil V, Durand J-P, Gillaizeau F, Niarra R, Jaeger C, et al. Effect of integrated palliative care on the quality of end-of-life care: retrospective analysis of 521 cancer patients. BMJ Support Palliat Care. 2012 Sep;2(3):239-47.

16. Wright AA, Zhang B, Keating NL, Weeks JC, Prigerson HG. Associations between palliative chemotherapy and adult cancer patients' end of life care and place of death: prospective cohort study. BMJ. 2014 Mar 4;348(mar04 4):g1219-g1219. 
17. Mack JW, Cronin A, Keating NL, Taback N, Huskamp HA, Malin JL, et al. Associations Between End-of-Life Discussion Characteristics and Care Received Near Death: A Prospective Cohort Study. J Clin Oncol. 2012 décembre;30(35):4387-95.

18. Grendarova P, Sinnarajah A, Trotter T, Card C, Wu JSY. Variations in intensity of end-of-life cancer therapy by cancer type at a Canadian tertiary cancer centre between 2003 and 2010. Support Care Cancer. 2015 Oct;23(10):3059-67.

19. Massa I, Nanni O, Foca F, Maltoni M, Derni S, Gentili N, et al. Chemotherapy and palliative care near end-of life: examining the appropriateness at a cancer institute for colorectal cancer patients. BMC Palliat Care. 2018;17(1):86.

20. Tanguy-Melac A, Aguade A-S, Fagot-Campagna A, Gastaldi-Ménager C, Sabaté J-M, Tuppin P. Management and intensity of medical end-of-life care in people with colorectal cancer during the year before their death in 2015: A French national observational study. Cancer Med. 2019 Nov;8(15):6671-83.

21. Gonçalves JF, Goyanes C. Use of chemotherapy at the end of life in a Portuguese oncology center. Support Care Cancer. 2008 Apr;16(4):321-7.

22. Viel E, Chaigneau L, Fanton E, Kalbacher E, Thiery-Vuillemnin A, Villanueva C, et al. Specific anticancer treatments in the last 3 months of life: a French experience. Support Care Cancer. 2013 Feb;21(2):405-12.

23. Rochigneux P, Raoul J, Beaussant Y, Aubry R, Goldwasser F, Tournigand C, et al. Use of chemotherapy near the end of life: what factors matter? Ann Oncol. 2016 Dec $19 ;$ mdw654.

24. Emanuel EJ, Young-Xu Y, Levinsky NG, Gazelle G, Saynina O, Ash AS. Chemotherapy use among Medicare beneficiaries at the end of life. Ann Intern Med. 2003 Apr 15;138(8):639-43.

25. Kao S, Shafiq J, Vardy J, Adams D. Use of chemotherapy at end of life in oncology patients. Ann Oncol. 2009 Sep 1;20(9):1555-9.

26. Gallais Sérezal I, Beaussant Y, Rochigneux P, Tournigand C, Aubry R, Lindelöf B, et al. End-of-life care for hospitalised patients with metastatic melanoma in France: a nationwide, register-based study. Br J Dermatol. 2016 avril;n/a-n/a.

27. Tang ST, Wu S-C, Hung Y-N, Chen J-S, Huang E-W, Liu T-W. Determinants of Aggressive End-of-Life Care for Taiwanese Cancer Decedents, 2001 to 2006. J Clin Oncol. 2009 Sep 20;27(27):4613-8.

28. Gonsalves WI, Tashi T, Krishnamurthy J, Davies T, Ortman S, Thota R, et al. Effect of Palliative Care Services on the Aggressiveness of End-of-Life Care in the Veteran's Affairs Cancer Population. J Palliat Med. 2011 Aug 30;14(11):1231-5.

29. Anshushaug M, Gynnild MA, Kaasa S, Kvikstad A, Grønberg BH. Characterization of patients receiving palliative chemo- and radiotherapy during end of life at a regional cancer center in Norway. Acta Oncol Stockh Swed. 2015 Mar;54(3):395-402.

30. Colombet I, Bouleuc C, Piolot A, Vilfaillot A, Jaulmes H, Voisin-Saltiel S, et al. Multicentre analysis of intensity of care at the end-of-life in patients with advanced cancer, combining health administrative data with hospital records: variations in practice call for routine quality evaluation. BMC Palliat Care. 2019;18(1):35.

31. Greer JA, Pirl WF, Jackson VA, Muzikansky A, Lennes IT, Heist RS, et al. Effect of Early Palliative Care on Chemotherapy Use and End-of-Life Care in Patients With Metastatic Non-Small-Cell Lung Cancer. J Clin Oncol. 2012 Feb 1;30(4):394-400.

32. Zimmermann C, Swami N, Krzyzanowska M, Hannon B, Leighl N, Oza A, et al. Early palliative care for patients with advanced cancer: a cluster-randomised controlled trial. The Lancet. 2014 May 17;383(9930):1721-30.

33. Zhang B, Nilsson ME, Prigerson HG. Factors important to patients' quality of life at the end of life. Arch Intern Med. 2012 Aug 13;172(15):1133-42. 
34. Fujisawa D, Temel JS, Traeger L, Greer JA, Lennes IT, Mimura M, et al.

Psychological factors at early stage of treatment as predictors of receiving chemotherapy at the end of life: Psychological factors and chemotherapy at end of life. Psychooncology. 2015 Dec;24(12):1731-7.

35. Barbot A-C, Mussault P, Ingrand P, Tourani J-M. Assessing 2-month clinical prognosis in hospitalized patients with advanced solid tumors. J Clin Oncol Off J Am Soc Clin Oncol. 2008 May 20;26(15):2538-43.

36. Maltoni M, Nanni O, Pirovano M, Scarpi E, Indelli M, Martini C, et al. Successful validation of the palliative prognostic score in terminally ill cancer patients. Italian

Multicenter Study Group on Palliative Care. J Pain Symptom Manage. 1999 Apr;17(4):240-7. 37. Bourgeois H, Grudé F, Solal-Céligny P, Dupuis O, Voog E, Ganem G, et al. Clinical validation of a prognostic tool in a population of outpatients treated for incurable cancer undergoing anticancer therapy: PRONOPALL study. Ann Oncol Off J Eur Soc Med Oncol. 2017 Jul 1;28(7):1612-7. 
Figure 1- Overall survival according chemotherapy treatment 1 month before death.

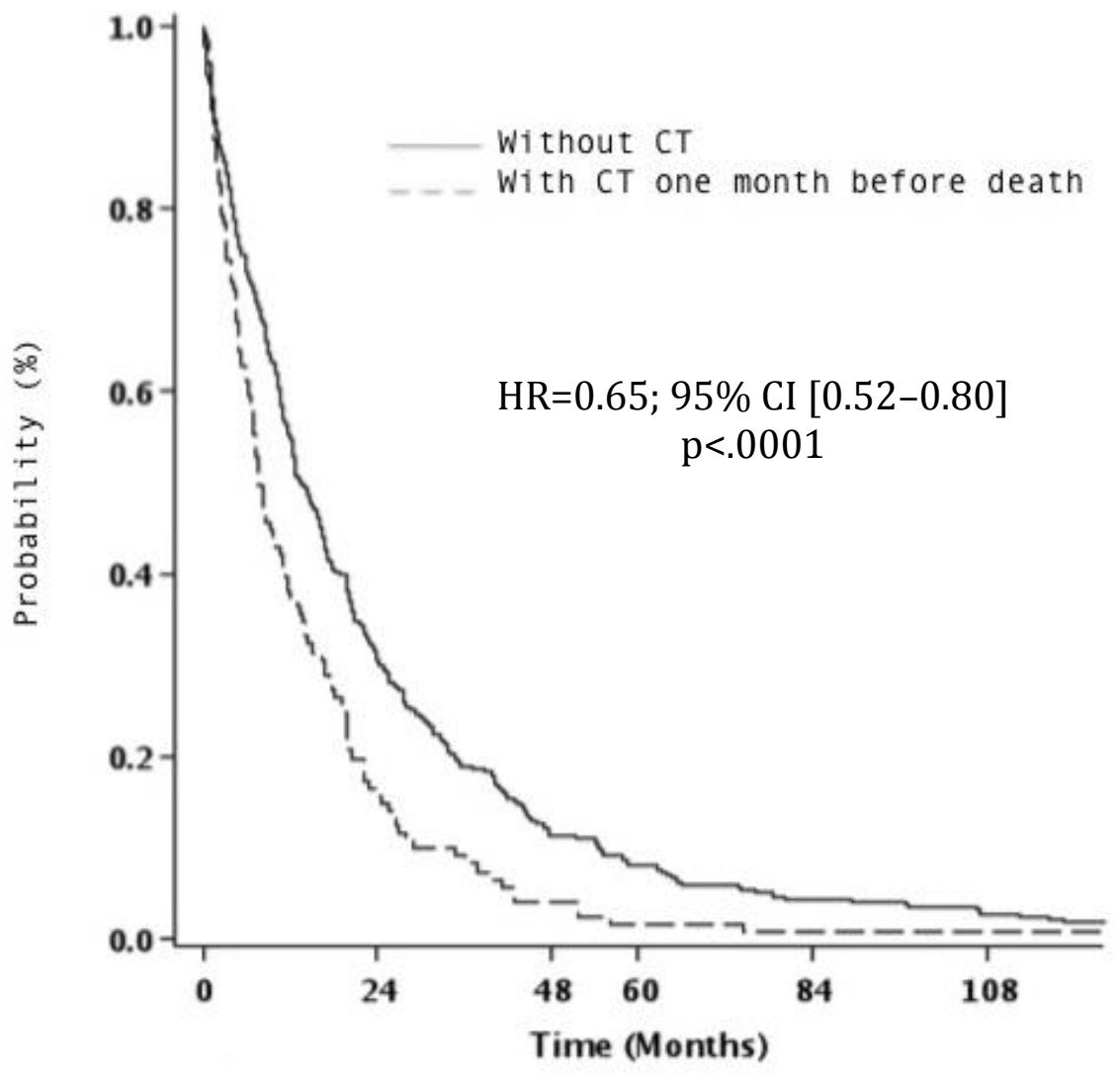

$\begin{array}{lllllllllll}\text { Without CT } 316 & 174 & 96 & 60 & 36 & 26 & 19 & 14 & 13 & 9 & 6\end{array}$

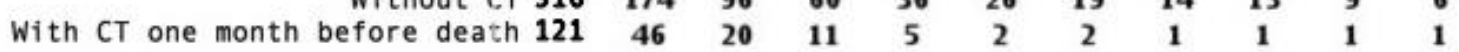




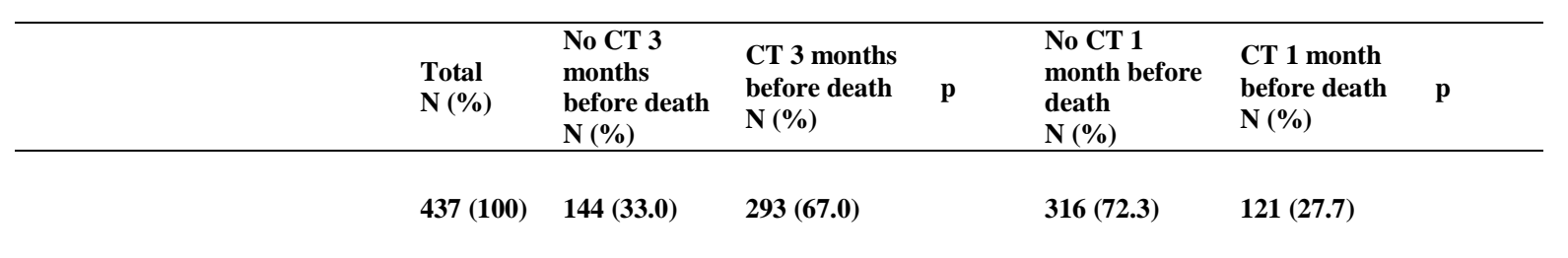

Gender

\begin{tabular}{|c|c|c|c|c|c|c|}
\hline Male & $281(64.3)$ & $95(66.0)$ & $186(63.5)$ & 0.6 & $213(67.4)$ & $68(56.2)$ \\
\hline Female & $156(35.7)$ & $49(34.0)$ & $107(36.5)$ & & $103(32.6)$ & $53(43.8)$ \\
\hline
\end{tabular}

Age at diagnostic

$\begin{array}{llllllll}\text { Median } & 67.5 & 72.8 & 65.5 & <.0001 & 67.9 & 65.4 & 0.036 \\ \text { Range } & {[27.2-} & {[34.5-98.60} & {[27.2-94.4]} & & {[28.3-98.6]} & {[27.2-94.4]} & \end{array}$

Tumor site

\begin{tabular}{|c|c|c|c|c|c|c|c|}
\hline Pancreas & $124(28.4)$ & $35(24.3)$ & $89(30.4)$ & 0.52 & $84(26.6)$ & $40(33.1)$ & 0.27 \\
\hline Stomach & $45(10.3)$ & $15(10.4)$ & $30(10.2)$ & & $33(10.4)$ & $12(9.9)$ & \\
\hline Colorectal & $158(36.1)$ & $53(36.8)$ & $105(35.8)$ & & $122(38.6)$ & $36(29.7)$ & \\
\hline Other & $110(25.2)$ & 41( & $69(23.6)$ & & $77(24.4)$ & $33(27.3)$ & \\
\hline \multicolumn{8}{|c|}{ Number of previous lines of CT } \\
\hline Median & 2 & 1 & 2 & $<.0001$ & 1 & 2 & 0.01 \\
\hline Range & {$[0-8]$} & {$[0-6]$} & {$[1-8]$} & & {$[0-8]$} & {$[1-8]$} & \\
\hline
\end{tabular}

Center

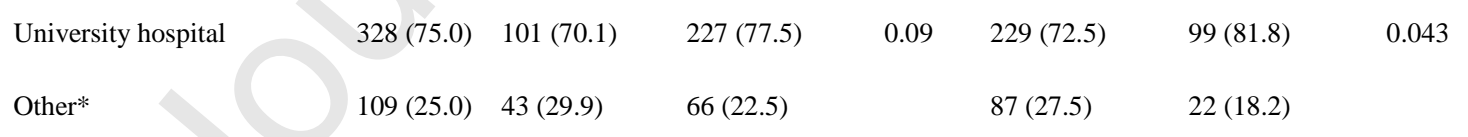

Patient and tumor characteristics 3 months before death

WHO performance status

\begin{tabular}{|c|c|c|c|c|c|c|}
\hline 0 & $29(6.6)$ & $8(5.6)$ & $21(7.2)$ & $<.0001$ & $23(7.3)$ & $6(5.0)$ \\
\hline 1 & $171(39.1)$ & $34(23.6)$ & $137(46.8)$ & & $109(34.5)$ & $62(51.2)$ \\
\hline 2 & 125 (28.6) & 37 (25.7) & $88(30.03)$ & & $91(28.8)$ & $34(28.1)$ \\
\hline
\end{tabular}


3

4

NA

\section{Albumin level (g/L)}

Median

Range

Missing data

Number of metastatic sites

0

1

2

3

4

Metastasis site

\section{Liver}

Yes

$276(63.2) \quad 80(55.6)$

$196(66.9)$

0.02

81 (66.9)

0.31

Lung

Yes

$143(32.7) \quad 42(29.2)$

101 (34.5)

103 (32.6)

40 (33.1)

0.26

0.92

\section{Peritoneum}

Yes

135 (30.9) 34 (23.6)

$101(34.5)$

0.02

$90(28.5)$

45 (37.2)

0.08

Other

$$
\text { Yes }
$$


Table 2 - Supportive care and hospitalizations

\begin{tabular}{|c|c|c|c|c|c|}
\hline $\begin{array}{l}\text { Total } \\
N=437\end{array}$ & $\begin{array}{l}\text { No CT } 3 \\
\text { months before } \\
\text { death } \\
N=144(33.0)\end{array}$ & $\begin{array}{l}\text { CT } 3 \text { months } \\
\text { before death } \\
N=293(67.0)\end{array}$ & $\mathbf{p}$ & $\begin{array}{l}\text { No CT } 1 \text { month } \\
\text { before death } \\
\mathrm{N}=316(72.3)\end{array}$ & $\begin{array}{l}\text { CT } 1 \text { month } \\
\text { before death } \\
\mathrm{N}=121(27.7)\end{array}$ \\
\hline
\end{tabular}

Palliative Care Team Intervention, $\mathbf{N}(\%)$

$\begin{array}{llllllll}\text { No } & 224(51.3) & 68(47.2) & 156(53.2) & 0.49 & 151(47.8) & 73(60.3) & 0.02 \\ \text { Yes } & \begin{array}{l}210 \\ (48.02)\end{array} & 75(52.8) & 135(46.1) & & 162(51.3) & 48(39.7) \\ & & & & & \\ \text { Missing data } & 3(0.7) & 1(0.7) & 2(0.68) & 3(0.9) & 0(0)\end{array}$

Hospitalization during the 3 months before death, N (\%)

$\begin{array}{lllllll}\text { No } & 19(4.4) & 5(3.5) & 14(4.8) & 0.53 & 14(4.4) & 5(4.1) \\ \text { Yes } & 418(95.6) & 139(96.5) & 279(95.2) & 302(95.6) & 116(95.9)\end{array}$

In-hospital stays (days) during the 3 months before death

$\begin{array}{ll}0.46 & 0.0001\end{array}$

$\begin{array}{llllll}\text { median } & 22 & 21.5 & 22 & 24 & 15 \\ \text { range } & {[0-92]} & {[0-86]} & {[0-92]} & {[0-92]} & {[0-76]} \\ & & & & & \\ \text { Missing data } & 6 & 2 & 4 & 3 & 3\end{array}$

Parenteral nutrition during the 3 months before death, $\mathbf{N}(\%)$

\begin{tabular}{|c|c|c|c|c|c|c|c|}
\hline No & $356(81.5)$ & $128(88.9)$ & $228(77.8)$ & 0.003 & $254(80.4)$ & $102(84.3)$ & 0.58 \\
\hline Yes & 75 (17.2) & $16(11.1)$ & $59(20.1)$ & & 57 (18.0) & 18 (14.9) & \\
\hline Missing data & $6(1.4)$ & $0(0)$ & $6(2.0)$ & & $5(1.6)$ & $1(0.9)$ & \\
\hline
\end{tabular}

Place of death 


\begin{tabular}{|c|c|c|c|c|c|c|c|}
\hline $\begin{array}{l}\text { Medical GI } \\
\text { oncology unit }\end{array}$ & $307(70.1)$ & $100(69.4)$ & $207(70.3)$ & 0.41 & $206(65.2)$ & $101(83.5)$ & 0.0009 \\
\hline PCU & $91(20.8)$ & 34 (23.6) & $57(19.4)$ & & 77 (24.4) & 14 (11.6) & \\
\hline Home & $39(8.9)$ & $10(6.9)$ & $29(9.9)$ & & $33(10.4)$ & $6(5.0)$ & \\
\hline \multicolumn{8}{|l|}{ Causes of death } \\
\hline Evolution of cancer & 366 (83.7) & $125(86.8)$ & $241(82.2)$ & 0.33 & $278(88.0)$ & $88(72.7)$ & 0.0003 \\
\hline Other acute cause & $54(12.4)$ & $13(9.0)$ & $41(14.0)$ & & $26(8.2)$ & $28(23.2)$ & \\
\hline Unknown & $17(3.9)$ & $6(4.1)$ & $11(3.7)$ & & $12(3.8)$ & $5(4.1)$ & \\
\hline \multicolumn{8}{|c|}{ Time (days) between transfer to palliative care unit and death } \\
\hline $\mathrm{n}$ & 104 & 33 & 71 & 0.72 & 89 & 15 & 0.02 \\
\hline median & 11.5 & 11.0 & 12.0 & & 14.0 & 7.0 & \\
\hline range & {$[0-155]$} & {$[0-155]$} & {$[0-110]$} & & {$[0-155]$} & {$[0-27]$} & \\
\hline
\end{tabular}


Table 3-Univariate and multivariate overall survival analysis

\begin{tabular}{|c|c|c|c|c|}
\hline & \multicolumn{2}{|c|}{ Univariate survival analysis } & \multicolumn{2}{|c|}{ Multivariate survival analysis } \\
\hline & HR (IC95\%) & $\mathbf{p}$ & HR (IC95\%) & $\mathbf{p}$ \\
\hline \multicolumn{5}{|l|}{ CT 1 month before death } \\
\hline No & $0.65(0.52-0.8)$ & $<.0001$ & $0.58(0.46-0.72)$ & $<.0001$ \\
\hline Yes & 1 & & 1 & \\
\hline \multicolumn{5}{|l|}{ Center } \\
\hline University hospital & 1 & 0.03 & 1 & 0.0006 \\
\hline Private center & $0.71(0.41-1.22)$ & & $0.68(0.40-1.18)$ & \\
\hline Non university hospital & $1.38(1.07-1.78)$ & & $1.59(1.22-2.06)$ & \\
\hline Comprehensive cancer center & $1.20(0.77-1.87)$ & & $1.57(1.0-2.46)$ & \\
\hline Age at diagnostic & $1.01(1.00-1.02)$ & $<.0001$ & $1.02(1.01-1.03)$ & $<.0001$ \\
\hline \multicolumn{5}{|l|}{$<67$ years } \\
\hline & $15,27(11,63-19,11)$ & 0,0013 & 1 & 0,001 \\
\hline \multicolumn{5}{|l|}{$\geq 67$ years } \\
\hline & $10,67(8,45-12,23)$ & $1,36(1,12-1,65)$ & $1.76(1.51-2.04)$ & $<0.0001$ \\
\hline \multicolumn{5}{|l|}{ Tumor site } \\
\hline Pancreas & 1 & $<.0001$ & 1 & $<.0001$ \\
\hline Stomach & $0.68(0.48-0.96)$ & & $0.72(0.50-1.02)$ & \\
\hline colon-rectum & $0.38(0.30-0.49)$ & & $0.40(0.31-0.52)$ & \\
\hline Other & $0.69(0.53-0.90)$ & & $0.70(0.53-0.92)$ & \\
\hline
\end{tabular}

*Factors that did not significantly influence survival in univariate analysis were : $\operatorname{sex}(\mathrm{p}=0.1)$, ECOG performance status 3 months before death $(\mathrm{p}=0.3)$, albumin level 3 months before death $(\mathrm{p}=0.6)$, palliative care team intervention $(\mathrm{p}=0.9)$, hospitalization in the last 3 months of life $(\mathrm{p}=0.9)$, parenteral nutrition 3 months before death $(\mathrm{p}=0.5)$, non-pulmonary metastasis 3 months before death $(\mathrm{p}=0.4)$

** Sixty-seven years is the median age of our population 
